\title{
Инновационная инфраструктура как драйвер развития региона
}

\author{
И. А. Тронина ${ }^{1 凶}$, Г. И. Татенко ${ }^{2}$, А. Е. Грекова ${ }^{3}$ \\ 1,2, 3 Орловский государственный университет имени И. С. Тургенева, \\ ул. Комсомольская, 95, 302026, Орел, Российская Федерация
}

Для цитирования: Тронина И. А., Татенко Г. И., Грекова А. Е. Инновационная инфраструктура как драйвер развития региона // Вестник Воронежского государственного университета. Серия: Экономика и управление. 2020. № 3. C. 101-112. DOI: 10.17308/econ.2020.3/3109

\begin{abstract}
Предмет. Инновационная инфраструктура представляет собой особую сферу деятельности, выполняющую обеспечивающие функции для инновационного развития региона. Согласно концепции формирования инновационных систем национального и регионального уровней инновационная инфраструктура должна включать два комплексных элемента: инфраструктуру диффузии инноваций и инновационную инфраструктуру общества. Причем первый элемент уделяет серьезное внимание не только распространению инноваций, но и кооперации и формированию партнерства участников инновационного процесса в регионе. Второй элемент отражает общие условия развития инновационного потенциала для хозяйствующих субъектов. Серьезная поддерживающая функция со стороны инновационной инфраструктуры способна стать драйвером инновационного развития территории, механизмом формирования актуальной на сегодняшний день инновационной культуры в инновационной среде региона.

Цели. Изучение вопросов создания и поддержания элементов инновационной инфраструктуры для решения проблемы инновационного развития региона на основе существующего теоретико-методического задела и практического опыта.

Методология. В процессе изучения вопросов функционирования и развития инновационной инфраструктуры в российской теории и практике использовались общенаучные методы познания, статистические методы исследования, а также принципы и методы системного подхода.

Результаты. В статье рассмотрены аспекты построения региональной экономики инновационного типа, инструменты и институты, обеспечивающие непрерывность инновационного процесса. Анализ существующего российского опыта формирования инновационной инфраструктуры подтверждает важность механизма поддержки инновационных проектов. Доказано, что драйвером инновационного развития региона является инновационная инфраструктура, поэтому особенно важны перспективы развития стимулирования инноваций и расширение сетевого взаимодействия. Выводы. Региональная экономика инновационного типа предполагает активный переход к экономике знаний, моделям открытых инноваций и четырехзвенной спирали, что требует формирования в регионах целостной системы преобразования новых знаний в новые технологии, продукты и услуги. Именно регионы должны стать активатором инновационной деятельности национального уровня. Поэтому для усиления регионального аспекта инновационного развития требуется создание благоприятных условий, обеспеченных инновационной инфраструктурой. Только с учетом решения задач развития инновационной инфраструктуры требуемого уровня можно говорить о достижении целей реализации инновационной политики и инновационной стратегии региона. Сложным вопросом остается проблема согласования интересов участников инновационного процесса, в том числе с помощью механизмов создания и поддержания элементов инновационной инфраструктуры.
\end{abstract}

Ключевые слова: инновационная инфраструктура, регион, инновационная экономика, инновационная деятельность.

\section{Введение}

Инновационный путь развития регионов на современном этапе отечественной и мировой экономики особенно важен для обеспечения экономической безопасности государства.
Это связано с тем, что на первый план выходят такие сложные вопросы, как социально-экономическое развитие систем разного уровня (от мировых макросистем до систем уровня компаний - микросистем); научно-техниче-

() Тронина И. А., Татенко Г. И., Грекова А. Е., 2020

Вестник ВГУ. Серия: Экономика и управление. 2020. № 3. С. 101-112. 
ское и технологическое развитие в контексте очередного уклада, определяющего использование сквозных цифровых технологий; формирование актуального уровня конкурентоспособности страны, региона, компании, продукта [1]. Все это переплетается с динамичностью, сложностью, неопределенностью внешней среды, скорректированной не только процессами глобализации и цифровизации, но и пандемии. Поэтому динамика устойчивого социально-экономического развития страны и ее регионов во многом определяется инновационными факторами, формирующими новые проекции «диверсификации и обновления технологических базисов для производства конкурентоспособных товаров и услуг», а значит повышения инновационной активности хозяйствующих субъектов различных сфер экономической деятельности [18].

Возвращаясь к истории экономического общественного развития, рассмотренным учеными-экономистами разным теориям и концепциям, можно отметить важность, а иногда и принципиальность инновационной составляющей на каждом этапе. Переход с этапа на этап, или с одного уклада на другой, всегда сопровождается активным инновационным процессом, предполагающим накопление инновационного потенциала, отвечающего задачам этапа (уклада), а также созданием необходимой инновационной инфраструктуры. В связи с этим вопросы создания, развития и поддержания инновационной инфраструктуры всегда являются актуальными, а значит представляющими научный и практический интерес в поиске лучших решений, связанных с формированием стратегии инновационного развития территорий [17].

Обзор литературных источников по исследуемой проблеме позволяет выделить теоретические разработки следующих ученых: В. А. Васин, Е. Б. Гончарова, И. Гурков, В. В. Деменок, Д. М. Дроненко, Н. В. Зубаревич, Л. К. Пипия, М. Портер, А. М. Садыков, Б. Санто и многие другие $[1 ; 5 ; 8 ; 14]$. Аспекты формирования и функционирования инновационной инфраструктуры рассмотрены в работах Г. С. Гамидова, Л. М. Гохберга, Т. А. Исмаилова, И. Дежиной, Г. В. Киселевой, П. А. Кузнецова, Е. Куценко, А. В. Савановича, И. Л. Туккеля и иных ученых и специалистов $[2 ; 11 ; 16]$.

Хотелось бы отметить, что, по мнению Е. Б. Гончаровой и Д. М. Дроненко, серьезно «изменилось отношение субъектов РФ к инновационной деятельности» в сторону актуальности и необходимости решения проблемы инно- вационного развития территорий через взаимодействие всех участников инновационного процесса, а «способность мобилизовать и использовать свои инновационные ресурсы приобретает решающее значение», что создает возможности для создания и внедрений инноваций [3]. И. Г. Дежина и В. В. Киселева развивают идею о необходимости усиления горизонтальных взаимодействий между участниками инновационной системы национального и регионального уровней, а роль инновационной инфраструктуры заключается в поддержании необходимого уровня совокупности подсистем, обеспечивающих доступ к различным ресурсам участников инновационной деятельности [4].

Если считать терминологически «инфраструктурой» объекты более низкого уровня иерархии по отношению к высшей функциональной системе, деятельность которой они обеспечивают, то инновационная инфраструктура - это прежде всего основание (фундамент) инновационной системы. Основными компонентами такого основания являются правовая, информационная, научная, финансовая составляющие. При этом исследователи инновационной инфраструктуры предлагают самые разные подходы к изучению этой категории: системный (Г. Е. Гамидов, Ж. Ю. Уланова); комплексный (А. Н. Мярин, О. В. Балакирева, А. В. Ширяев); структурно-функциональный (Е. В. Борисова, И. Г. Дежина, В. Г. Колосов, Н. О. Османов). Однозначно определяются практически всеми авторами базовые цели инновационной инфраструктуры, заключающиеся в грамотном обеспечении процессов инновационной деятельности, повышении инновационной активности участников инновационной системы, создании диффузии инноваций.

Наличие развитой инновационной инфраструктуры необходимо территории любого уровня для более эффективного использования ее научно-технического и инновационного потенциала. Именно инновационная инфраструктура, на наш взгляд, как поддерживающий компонент инновационной системы способна достаточно быстро и правильно перенести современные фундаментальные знания в актуальную социально-экономическую практику [10]. Хочется отметить, что развитая инновационная инфраструктура не просто стимулирует инновационную деятельность и инновационную активность хозяйствующих субъектов, но и создает благоприятные условия для реализации целей социально-экономического развития территории, поддерживая эффективную работу 
механизмов государственного регулирования. Следовательно, в процесс формирования стратегии инновационного развития территории необходимо включать организационно-экономические механизмы создания и поддержания элементов инновационной инфраструктуры.

Исходя из этого, целью данного исследования будем считать изучение теоретических конструкций, методических приемов и практического опыта формирования инновационной инфраструктуры с позиции решения проблемы инновационного развития территории. Для достижения поставленной цели необходимо решение следующих задач: рассмотреть проблемы формирования инновационной инфраструктуры как базового условия обеспечения конкурентоспособности региона; изучить основные компоненты инновационной инфраструктуры в российской практике; определить движущие механизмы развития инновационной инфраструктуры как драйвера инновационного развития территории.

\section{Материалы и методы исследования}

Теоретической и методологической основой исследования послужили научные труды, прикладные исследования отечественных и зарубежных авторов в области инновационного развития территории и формирования инновационной инфраструктуры. Методологическую базу исследования составили общенаучные методы познания, статистические методы исследования, а также принципы и методы системного подхода. Информационная составляющая исследования включает данные российской государственной статистики, справочные данные из отечественной и научной литературы, материалы научно-практических конференций, а также информацию научных журналов и интернет-среды.

\section{Обсуждение результатов}

Изучая существующий в научной литературе теоретико-методологический материал, сформированный учеными-экономистами, мы приходим к выводу, что для российских регионов по-прежнему нерешенными остаются вопросы формирования механизма распространения и оценки характера воздействия инновационных процессов на экономический рост. Во многом такая ситуация, по нашему мнению, обусловлена значительной дифференциацией регионального развития в РФ, несопоставимостью параметров для оценки потенциала инновационного развития территорий [15].
В связи с этим хочется отметить многоукладность современной российской экономики, подчеркивающей неравномерность и неравноценность технологического базиса (каждый технологический уклад находится в определенной фазе своего жизненного цикла - стагнации и отмирания, зрелости, интенсивного роста или в фазе зарождения). Поэтому такая ситуация «многоукладности» действует губительно на каждом этапе жизненного цикла и порождает множество отрицательных явлений, проблемных точек в инновационном развитии региона, среди которых стоит отметить следующие:

- низкий уровень взаимодействия основных стейкхолдеров инновационного процесса в регионе согласно модели четырехзвенной спирали инноваций (государство, бизнес-сообщество, гражданское сообщество, наука и образование);

- низкий уровень производства и внедрения инноваций как следствие недостаточных усилий со стороны государственного управления инновационным процессом;

- неопределенность в институциональной структуре инновационной системы, подкрепленная наличием высоких рисков;

- недостаточная инновационная активность бизнес-сообщества и слабая мотивация для активизации их инновационной деятельности;

- неопределенность в законодательной и нормативно-правовой базе развития венчурной индустрии со слабой поддержкой для их функционирования в российских условиях;

- недостаточное инвестирование в исследования и разработки со стороны государства с оторванностью интересов стейкхолдеров в развитии инновационной системы регионального уровня;

- низкий уровень инновационной инфраструктуры, поддерживающей инновационный процесс на региональном уровне и создающей базис для активизации инновационной деятельности хозяйствующих субъектов.

Опираясь на исследования проблемы функционирования и развития инновационной инфраструктуры в российских условиях, отраженных в источниках открытой информации, выделим базовые принципы формирования инновационной инфраструктуры региона с рыночной ориентацией:

- самостоятельная координация действий со стороны инновационной инфраструктуры, а также межрегиональное инфраструктурное взаимодействие; 
- комплексный характер инфраструктурных действий с учетом задач каждого этапа инновационного процесса;

- сохранение и укрепление существующих организационных звеньев инфраструктуры;

- актуальность инфраструктуры уровню регионального научно-технического, инновационного, производственно-технологического потенциала;

- соответствие элементов инновационной инфраструктуры положениям действующих федеральных и региональных правовых и нормативных актов;

- наличие «здоровой» конкуренции между инфраструктурными звеньями для повышения эффективности инновационной деятельности;

- использование лучших отечественных и зарубежных практик в формировании механизма инфраструктурного развития региона;

- акцент на уникальность территории в разработке механизмов развития инновационной инфраструктуры.

В последние годы в России идет формирование системного комплекса инновационных инфраструктур и ожидается, что такой подход станет катализатором эффективного развития экономики РФ в целом и ее регионов в отдельности [13]. В рамках данного исследования ин- новационная инфраструктура Москвы интересна для изучения в качестве базового объекта и показательного примера. Здесь процесс протекает достаточно успешно, уже насчитывается более 1500 объектов инновационной инфраструктуры. Деятельность по проектированию объектов инновационной инфраструктуры задействовала множество столичных предприятий и организаций, при этом огромное количество инициативных людей вовлечены в создание стартапов. Формированием объектов инновационной инфраструктуры активно заняты частные и государственные технопарки, отраслевые институты и научно-промышленные кластеры. Эксперты отмечают положительную тенденцию такой занятости, по их мнению, инновации вскоре станут базисом будущей региональной экономики. Положительная динамика также подтверждается значениями в международных и национальных рейтингах конкурентоспособности, где Москва лидирует по многим позициям. «В столице успешно функционируют более 400 центров развития производственных технологий, на сегодняшний день у каждого предпринимателя есть доступ к высокотехнологичным продуктам для реализации планов и развития бизнеса» [3]. На рис. 1 показаны основные объекты инновационной инфраструктуры.

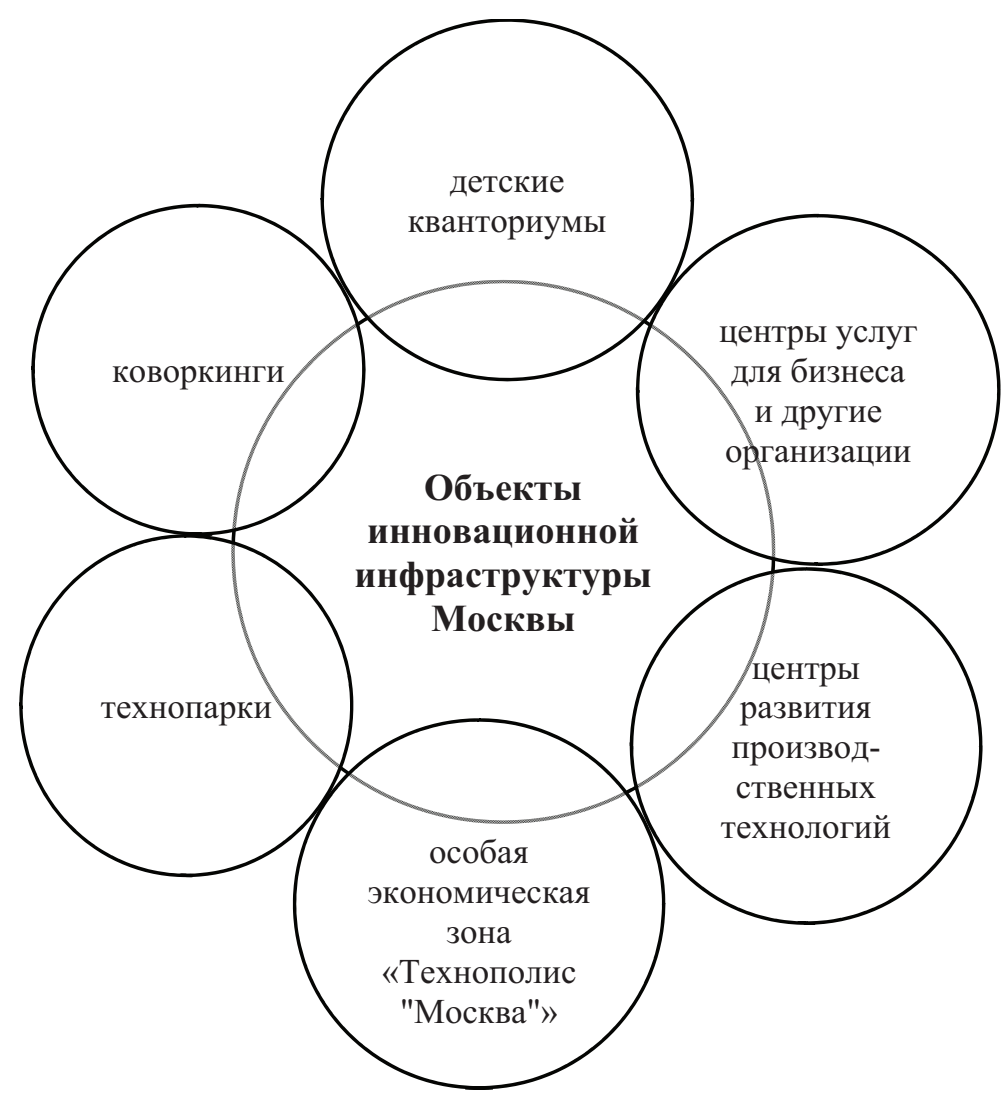

Puc. 1. Объекты инновационной инфраструктуры Москвы 
На наш взгляд, технопарки и особые экономические зоны являются важнейшими объектами столичной инновационной инфраструктуры, поскольку именно они генерируют наибольшее количество резидентов, разрабатывающих стартапы. На площадках для таких компаний создаются преференционные условия: налоговые каникулы, особые условия оплаты арендной платы; предоставлен доступ к необходимому высокотехнологичному оборудованию, помещениям, услугам [16]. Эффективным инфраструктурным объектом также можно считать коворкинг как сервисный инновационный инструмент для бизнеса, при этом создающий дополнительные рабочие места.

Что касается инновационных кластеров Москвы, особенно хочется отметить кластер микроэлектроники и приборостроения, базирующийся в Зеленограде, и кластер производства инновационных материалов, лазерных и радиационных технологий, располагающийся в Троицке. Большая часть продукции, производимой в инновационных кластерах, поставляется в департаменты здравоохранения, информационных технологий, строительства, транспорта и ЖКХ столицы. В рамках поддержки таких компаний регулярно проводятся презентационные мероприятия.

В Москве активно развивают инновационную экосистему в целях совершенствования города для привлечения инвестиций в высокие технологии. Не так давно разработали онлайн-навигатор, помощник для ориентации компаний в инновационной инфраструктуре Москвы. Навигатор связан с порталом, который наполнен необходимой информацией: интерактивной картой объектов инновационной инфраструктуры; личным кабинетом, позволяющим забронировать место в коворкинге; подборкой новостей в инновационной сфере [5].

В рамках исследования проблем развития инновационной инфраструктуры в противовес столичным объектам были изучены южные регионы, которые также считаются «инновационно»-активными. По сравнению со столичным регионом успех южных инноваций не столь яркий. Несмотря на это, в научной литературе и мировой практике роль локомотива возлагается на региональные власти и институты развития.

По данным аналитического центра «Эксперт Юг», проводившего анкетирование 55 компаний Ростовской области и Краснодарского края, а также интервьюирование руководителей 16 компаний и организаций, занимаю- щихся производством инновационной продукции или поддержкой инновационных компаний, инвестируют в инновации в подавляющем большинстве собственные средства, но при этом план инвестиций имеют и реально придерживаются его лишь 10 \% предприятий. Рисунки 2 и 3 иллюстрируют отдельные проблемы инновационного развития южных территорий [9].

По данным Росстата, затраты организаций на технологические инновации на юге России растут. В целом по ЮФО по итогам 2019 г. они выросли на 34,7 \% по сравнению с 2018 г., составив 126,2 млрд рублей. В Ростовской области сумма инвестиций равна 48,7 млрд рублей, а в Краснодарском крае - 57,3 млрд (рост в три раза). По итогам 2019 г. Ростовская область также уступила пальму первенства региона лидера на Юге по объему отгруженных инновационных товаров и услуг - опять же Краснодарскому краю, который никогда регионом-лидером в сфере инноваций не считался [9].

Таким образом, можно сделать вывод о важной роли инновационной инфраструктуры в стратегии инновационного развития территорий, поскольку первая компонента обеспечивает возможность эффективной реализации второй [20].

Кроме того, адекватная инновационная инфраструктура способна стать драйвером инновационного развития территории, движущие механизмы которого представлены на рис. 4.

Опираясь на результаты проведенного исследования, можно дать следующую формулировку понятию инновационная инфраструктура региона - это комплекс взаимосвязанных элементов, актуально необходимых для организации и реализации инновационной деятельности заинтересованных сторон - участников инновационного процесса и обеспечивающих взаимодействие в работе данных участников с целью разработки и внедрения инноваций [19]. Причем формирование подобной инновационной инфраструктуры возможно двумя путями: «сверху-вниз» и «снизу-вверх». Традиционный подход предполагает процесс формирования «сверху», когда инициативный посыл идет от наднациональных, национальных и региональных органов власти к бизнес-структурам «на местах». Формируется некая централизованная вертикаль субординации в инновационной деятельности, задающая инновационные ориентиры в законодательном порядке, под цели которых фор- 


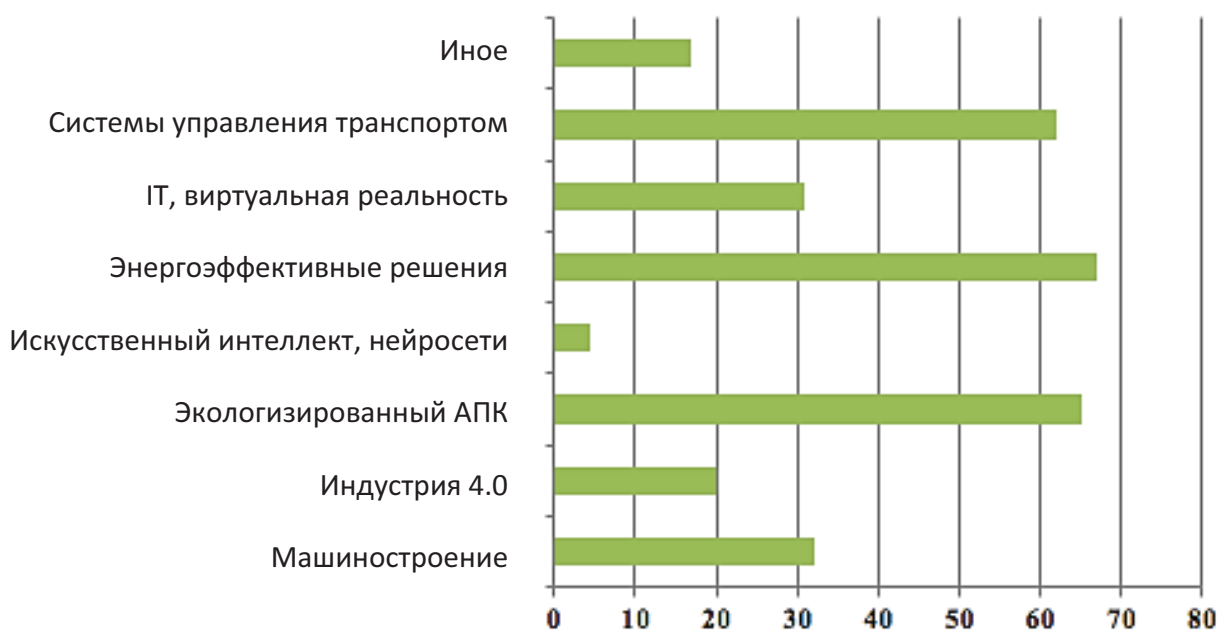

Отрасли юга России с наибольшим инновационным потенциалом

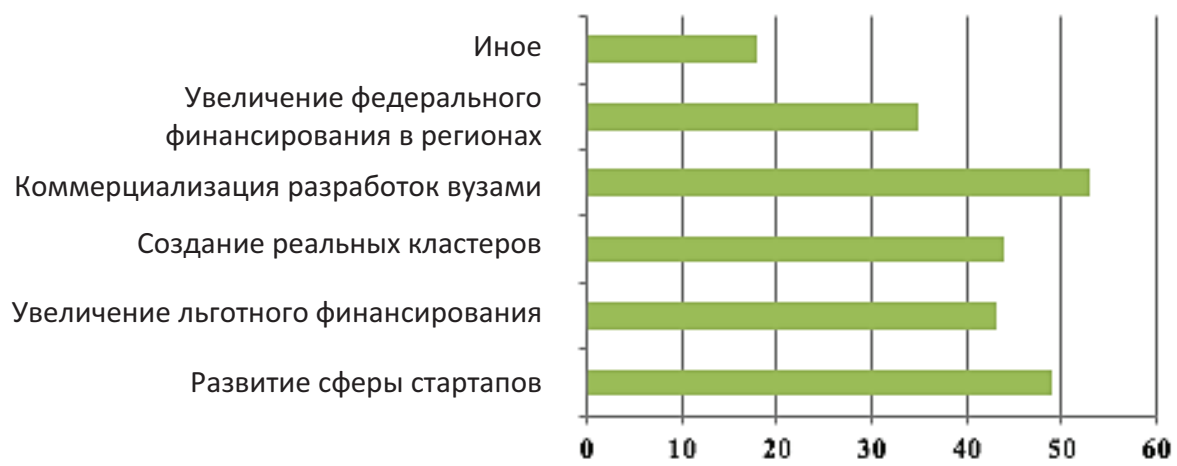

Важность и необходимость задач в сфере инновационного развития

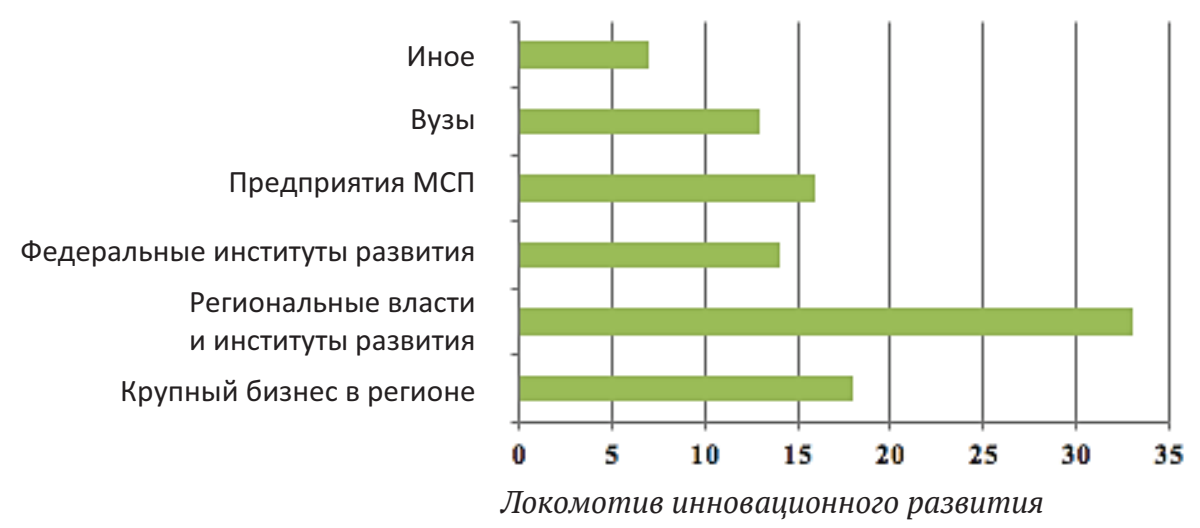

Puc. 2. Состояние инновационного развития южных регионов РФ (источник: аналитический центр «Эксперт Юг»)

мируются элементы инновационной инфраструктуры. Задача бизнес-структур заключается в этом случае в разработке позиционной стратегии своего инновационного развития в формате установленных «сверху» регламентов. Основное преимущество данного подхода заключается в том, что бизнес-сообщество встраивает свою инновационную деятельность в шаблон инновационной стратегии развития региона.
Радикальный подход предполагает формирование инновационных инициатив «снизу», т. е. инновационная активность берет свое начало «на местах» возникновения проблем, для решения которых необходимы инновации. У бизнес-структур нет полноценной возможности заниматься инновациями, поскольку это всегда дорогостоящий, системный и даже комплексный процесс, который обязательно должен быть подкреплен соответствующей 


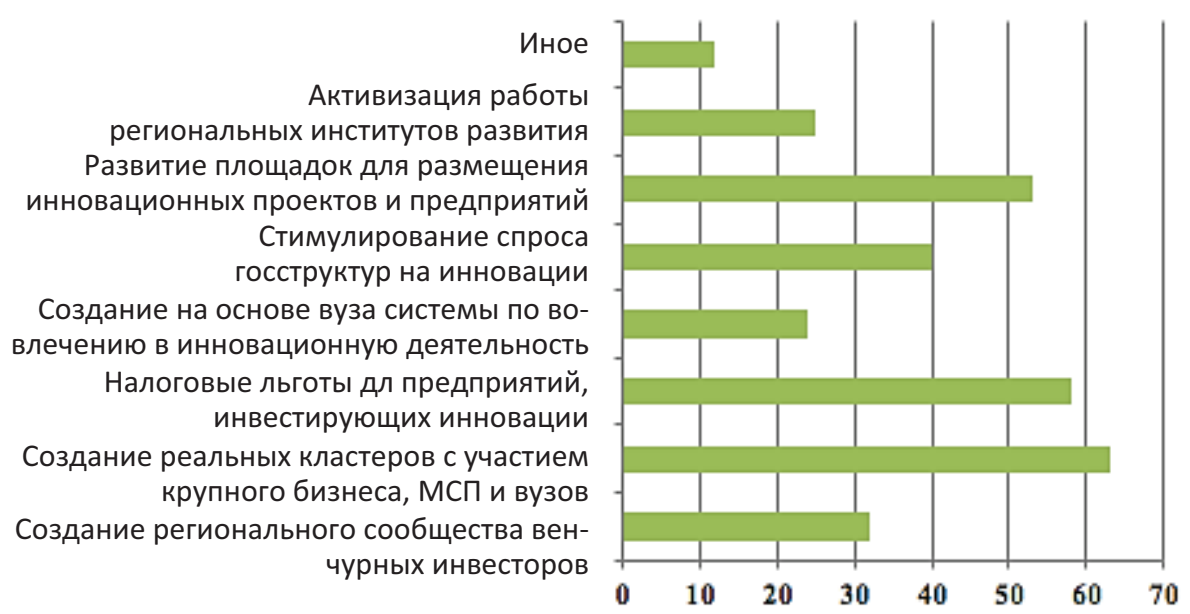

Необходимые изменения в инфраструктуре для поддержания инноваций как драйвера экономического роста

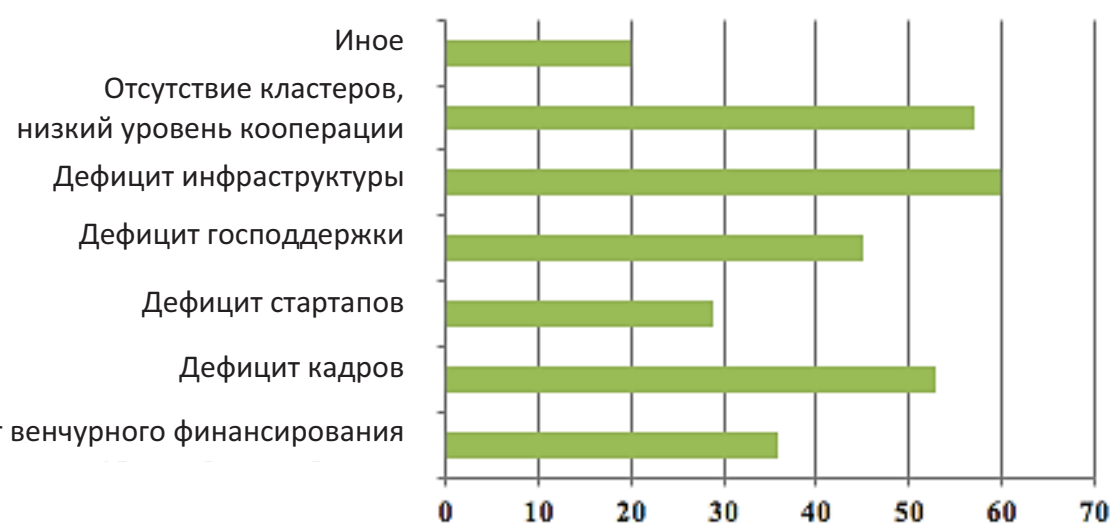

Препятствия для развития инноваций в регионе

Дефицит венчурного финансирования

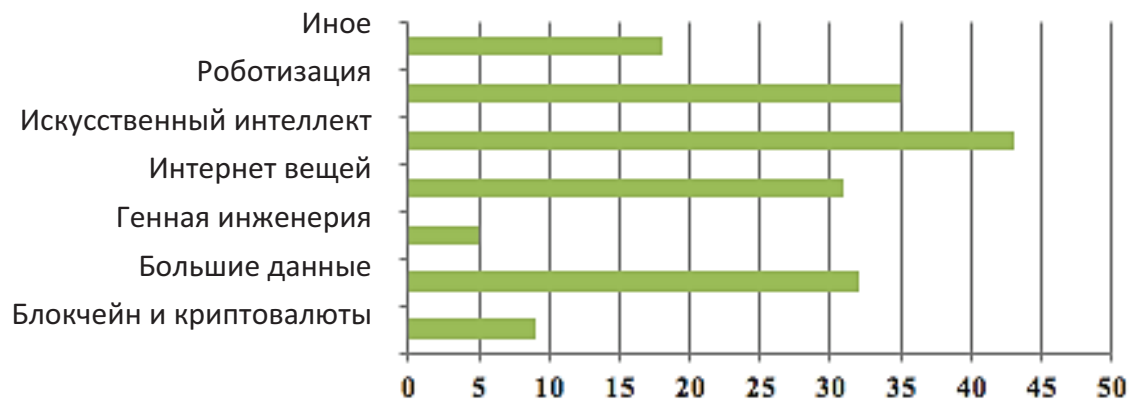

Влияние новых индустрий на стратегию инновационных инфраструктур региона

Puc. 3. Проблемы инновационного развития южных регионов РФ (источник: аналитический центр «Эксперт Юг»)

инфраструктурой. Поэтому представители различных бизнес-структур, заинтересованные в защите и продвижении своих интересов, выстраивают цепочку взаимодействия с региональными, национальными и, если необходимо, наднациональными государственными структурами. Главная особенность и преимущество такого подхода заключается в том, что бизнес-сообщество занимает активную позицию в инновационном процессе, развивая тем самым инновационную деятельность не только хозяйствующего субъекта, но и территории. Тем не менее нужна «золотая середина», создающая баланс интересов участников инновационной деятельности в формировании стратегии инновационного развития региона. Необходимо вовлечение всех групп заинтересованных сторон в процесс «предпринимательского поиска» согласно европейской концепции «умной специализации» [12]. По- 


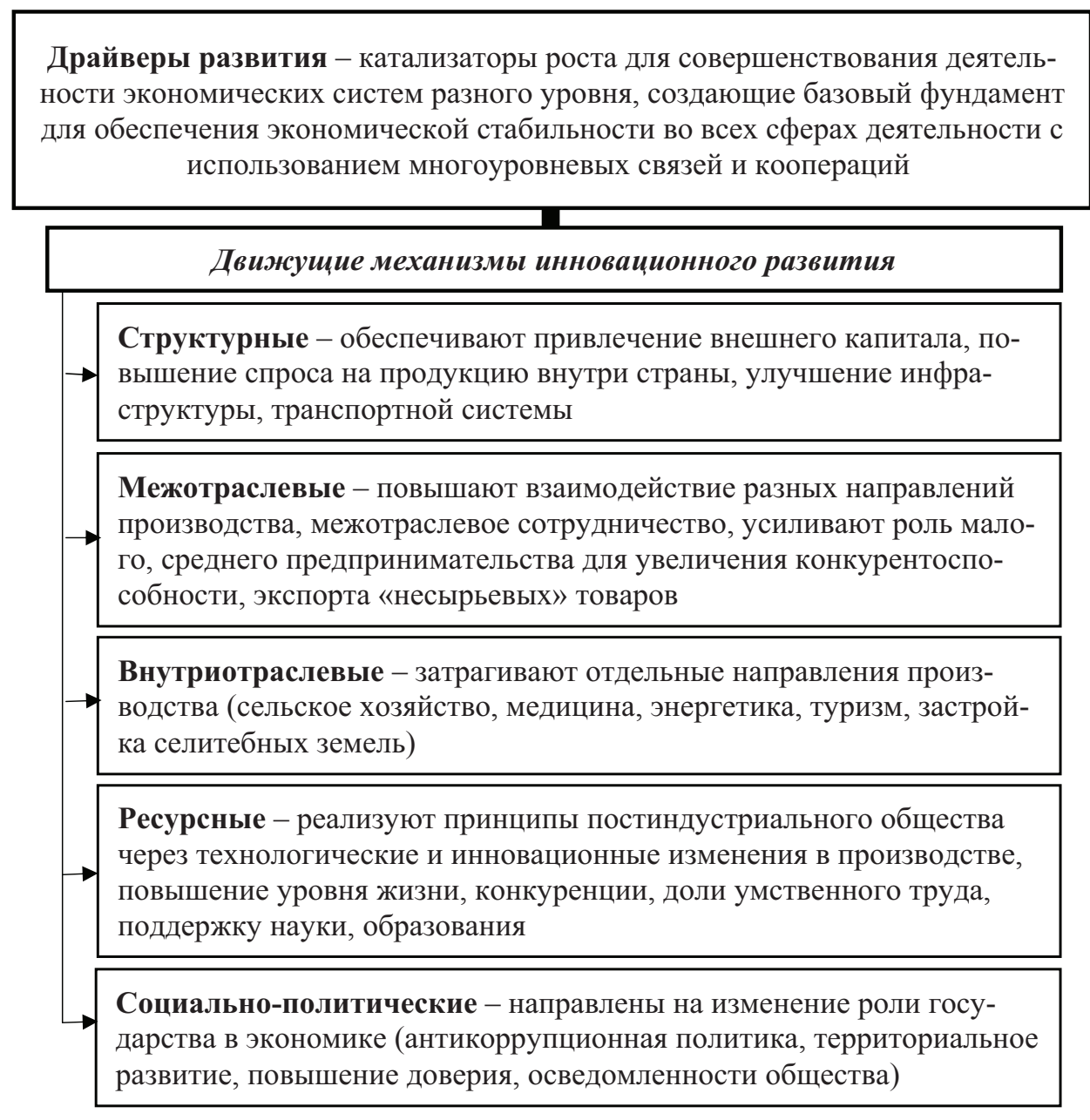

Puc. 4. Движущие механизмы инновационного развития

этому важно обеспечить трансформацию централизованной системы поддержки промышленности и предпринимательства к децентрализованной, рыночной, при которой перед государственными структурами первоочередной задачей является нахождение и реализация частным сектором собственных инновационных решений [7].

\section{Заключение}

Резюмируя все вышесказанное, можно сделать следующие выводы:

- в силу значительной дифференциации регионального инновационного развития в РФ и «многоукладности» современной российской экономики требуется смешанный подход, балансирующий инициативы «сверху» и «снизу» для поиска лучшего решения проблемы инновационного развития территории с учетом ее уникальности;

- вопросы развития и поддержки инновационной инфраструктуры в регионах актуаль- ны и чрезвычайно важны, поскольку без их решения невозможно адекватное функционирование инновационных систем разного уровня в соответствии с вызовами внешней среды;

- для целей развития инновационной инфраструктуры важен не только процесс «диффузии инновации», но и обеспечение сотрудничества и партнерства всех участников (стейкхолдеров) инновационного процесса согласно модели «четырехзвенной спирали инноваций»;

- в процесс формирования инновационной инфраструктуры необходимо интегрировать проработку «движущих» механизмов инновационного развития (структурные, межотраслевые, внутриотраслевые, ресурсные, социально-политические);

- к решению проблемы формирования инновационной инфраструктуры необходимо подходить системно и комплексно, вовлекая в инновационный процесс все большее количество участников, опираясь на отечественный и зарубежный опыт; 
- тем не менее, перенимая лучшие столичные практики и примеры южных регионов, стоит не забывать об уникальности и самобытности каждого региона РФ, делая акцент на них при разработке и реализации стратегии инновационного развития территории;

- в целевую основу всех действий развивающего характера должен быть положен тезис: «инновации как базис развития региональной экономики».

Проведенные исследования позволяют выделить следующие важные задачи, решение которых должно стать приоритетным для инновационного развития регионов:

- активная работа в формате «инновационной грамотности» с территориями-аутсайдерами, характеризующимися низкой долей занятого населения, устаревшими отраслями производства;

- вовлечение вузов в разработки стартапов и научные исследования для нужд бизнеса;

- вовлечение крупного бизнеса в создание региональных кластеров с инновационным акцентом;

- поддержка «инновационно»-активных бизнес-структур и отдельных инноваторов через налоговое стимулирование и развитие рынка инвестиций;

- расстановка инновационных акцентов на приоритетность таких сфер, определяющих уровень жизни и конкурентоспособности, как наука, образование, здравоохранение, социальное обеспечение;

- развитие инновационной инфраструктуры для обеспечения инновационной деятельности и объединения усилий заинтересованных сторон в единый процесс взаимодействия с учетом баланса интересов.

Переход к новому технологическому укладу возможен в том случае, когда подготовлена и развита необходимая инфраструктура, обеспечивающая адекватный процесс включения инноваций и достижений научно-технического прогресса в текущую деятельность социальноэкономических систем разных уровней. Аналогично этому для перехода к новому этапу инновационного развития - инновационной модели

\section{Библиографический список}

1. Васин В. А., Миндели Л. Э. Национальная инновационная система в социально-экономическом пространстве. М. : ИПРАН, 2011. 239 с.

2. Гамидов Г. С., Исмаилов Т. А., Туккель И. Л. Инновационная экономика: стратегия, политика, экономики за счет научного потенциала и развития высокотехнологичного производства и наукоемкого экспорта - стоит серьезно задуматься об уровне существующей инновационной инфраструктуры и направлениях ее совершенствования в соответствии с возможностями использования сквозных цифровых технологий [6]. Именно в этом и проявляется обоснованная необходимость изучения и проектирования инновационной инфраструктуры как драйвера развития региона. Поэтому можно с уверенностью утверждать, что именно инновационная инфраструктура способна катализировать развитие региона и делать его локомотивом инновационного процесса.

Поскольку инновационная инфраструктура по сути своей должна способствовать обеспечению деятельности инновационной системы региона, априори она является механизмом поддержки взаимодействия и сотрудничества всех участников инновационного процесса. Поэтому направления дальнейших исследований авторов связаны с постановкой проблемы и поиском решений организации взаимодействия стейкхолдеров и их вовлечения в процесс инновационного развития территории. Также актуальным вопросом считаем межрегиональное взаимодействие и создание на этой основе инфраструктурного партнерства. Кроме того, научный интерес представляет изучение вопросов формирования инновационной культуры в инновационной среде региона и, соответственно, роли инновационной инфраструктуры в этом сложном, но важном процессе.

\section{Источник финансирования}

Данная статья подготовлена при поддержке Российского фонда фундаментальных исследований в рамках проекта 19-010-00144 на тему «Управление инновационным развитием территорий: концепция «умной специализации»» в российских условиях».

\section{Конфликт интересов}

Авторы декларируют отсутствие явных и потенциальных конфликтов интересов, связанных с публикацией настоящей статьи.

решения : монография. СПб. : Политехника, 2007. $356 \mathrm{c.}$

3. Гончарова Е. Б., Дроненко Д. М. Развитие инновационного потенциала территории (региональный и муниципальный аспекты) : монография. Волгоград : ИУНЛ ВолгГТУ, 2013. 172 с. 
4. Дежина И. Г., Киселева В. В. Государство, наука и бизнес в инновационной системе России. М. : ИЭПП, 2008. 227 с.

5. Деменок В. В., Ремина Г. В., Саванович А. В. Инновационный аспект развития малого предпринимательства в регионе // Актуальные проблемы инновационной экономики и стратегического управления в Калининградской области: сборник научных трудов / БФУ им. И. Канта. Калининград : БФУ им. И. Канта, 2017. С. 97-101.

6. Евсеев О. С., Коновалова М.Е. Развитие инновационной инфраструктуры в условиях модернизации национальной экономики // Фундаментальные исследования. 2012. № 9-1. С. 220-224.

7. Земцов С. П., Баринова В. А. Смена парадигмы региональной инновационной политики в России: от выравнивания к умной специализации // Вопросы экономики. 2016. № 10. С. 65-81.

8. Зубаревич Н. В. Региональная проекция нового российского кризиса // Вопросы экономики. 2015. № 4. С. 37-52.

9. Козлов В., Ракуль Е. Как превратить инновации в драйвер - версия южного бизнеса // «Эксперт ЮГ». 2018. № 12 (420).URL:https://expert.ru/south/2018/12/ kak-prevratit-innovatsii-v-drajver-versiya-yuzhnogobiznesa/ (дата обращения: 20.04.2020).

10. Кузнецов П. А., Коршенко О. П., Коршенко И. Ф. Инновационная инфраструктура для различных типов стратегий регионального инновационного развития // Инновации. 2013. № 10 (180). С. 51-57.

11. Куценко Е. С., Абашкин В. Л., Исланкина Е. А. Фокусировка региональной промышленной политики через отраслевую специализацию // Вопросы экономики. 2019. № 5. С. 65-89.
12. Куцеенко Е. С., Исланкина Е. А., Киндрась А. Можно ли быть умным в одиночестве? Исследование инновационных стратегий российских регионов в контексте умной специализации // Форсайт. 2018. T. 12, № 1. С. 25-45.

13. Медынский В. Г., Скамай Л. Г. Инновационное предпринимательство. М. : Инфра-М, 2016. 588 с.

14. Пипия Л. К. Современные тенденции формировании научной и инновационной политики // Инновации. 2018. № 12. С. 61-62.

15. Рейтинг инновационного развития субъектов Российской Федерации. Вып. 5 / Г. И. Абдрахманова, П. Д. Бахтин, Л. М. Гохберг [и др.] ; под ред. Л. М. Гохберга ; Нац. исслед. ун-т «Высшая школа экономики». М. : НИУ ВШЭ, 2017. 260 с.

16. Саванович А. В. О концепции управления развития региональной инфраструктуры малого инновационного предпринимательства // Вестник БФУ им. И. Канта. 2016. Вып. 3. С. 105-109.

17. Сафиуллин Н. Ф. Модель управления инновационным развитием территории // Статистика и Экономика. 2013. № 1. С. 86-90.

18. Татаркин А. И., Суховей А. В. Построение инновационной экономики в РФ: проблемы и перспективы // Инновации. 2017. № 7. С. 11-15.

19. Татенко Г. И., Грекова А. Е. Инновационные инфраструктуры в российской и зарубежной практике // Экономические и гуманитарные науки. 2020. № 4 (339). С. 3-14.

20. Тронина И. А., Татенко Г. И., Бахтина С. С. Методология управления инновационным развитием территорий на принципах европейской концепции «умной специализации»: монография. Орел : ОГУ им. И. С. Тургенева, 2019. 206 с.
Тронина Ирина Алексеевна, доктор экономических наук, заведующий кафедрой менеджмента и государственного управления, Орловский государственный университет имени И. С. Тургенева, Орел, Российская Федерация

E-mail: irina-tronina@yandex.ru

ORCID ID: 0000-0002-9593-5129

Татенко Галина Ивановна, кандидат экономических наук, доцент кафедры менеджмента и государственного управления, Орловский государственный университет имени И. С. Тургенева, Орел, Российская Федерация

E-mail: galinatatenko@yandex.ru

ORCID ID: 0000-0002-6491-2370

Грекова Алина Евгеньевна, аспирант кафедры менеджмента и государственного управления, Орловский государственный университет имени И. С. Тургенева, Орел, Российская Федерация

E-mail: 79208025103@yandex.ru

ORCID ID: 0000-0001-8075-4803

Поступила в редакцию 17.06.2020

Подписана в печать 10.09.2020 


\title{
Innovative infrastructure as a driver of regional development
}

\author{
I. A. Tronina ${ }^{1 凶, ~ G . ~ I . ~ T a t e n k o ², ~ A . ~ E . ~ G r e k o v a ~}{ }^{3}$
}

${ }^{1,2,3}$ Orel State University named after I. S. Turgenev, 75 Komsomolskaya str., 302026, Orel, Russian Federation

Cite as: Tronina, I. A., Tatenko, G. I., Grekova, A. E. (2020) Innovative infrastructure as a driver of regional development. Proceedings of Voronezh State University. Series: Economics and Management. 3, 101-112. (In Russ., abstract in Eng.). DOI: 10.17308/econ.2020.3/3109

\begin{abstract}
Importance. Innovation infrastructure is a special area of activity that provides support functions for the innovative development of the region. According to the concept of formation of innovation systems at the national and regional levels, innovation infrastructure should include two complex elements: "infrastructure of diffusion of innovations" and "innovative infrastructure of society". Moreover, the first element pays serious attention not only to the spread of innovations, but also to cooperation and partnership of participants in the innovation process in the region. The second element, respectively, reflects the General conditions for the development of innovative potential for economic entities. A serious support function from the innovative infrastructure can become a driver of innovative development of the territory, a mechanism for the formation of an up-to-date innovative culture in the innovative environment of the region. Objectives. Study of issues of creating and maintaining elements of innovative infrastructure to solve the problem of innovative development of the region based on the existing theoretical and methodological background and practical experience.

Methods. In the process of studying the issues of functioning and development of innovation infrastructure in Russian theory and practice, General scientific methods of knowledge, statistical research methods, as well as principles and methods of the system approach were used.

Results. The article considers aspects of building a regional economy of an innovative type, tools and institutions that ensure the continuity of the innovation process. The analysis of the existing Russian experience in the formation of innovative infrastructure confirms the importance of the mechanism for supporting innovative projects. It is proved that innovative infrastructure is the driver of innovative development in the region. in this regard, the prospects for stimulating innovation and expanding network interaction are particularly important.

Conclusions and Relevance. The regional economy of the innovation type implies an active transition to the knowledge economy, open innovation models, and a four-link spiral, which requires the formation of an integrated system for converting new knowledge into new technologies, products, and services in the regions. It is the regions that should become the activator of innovation at the national level. Therefore, to strengthen the regional aspect of innovative development, it is necessary to create favourable conditions provided with innovative infrastructure. Only by taking into account the tasks of developing the required level of innovation infrastructure can we talk about achieving the goals of implementing the innovation policy and innovation strategy of the region. The problem of coordinating the interests of participants in the innovation process, including through mechanisms for creating and maintaining elements of the innovation infrastructure, remains a complex issue.
\end{abstract}

Key words: innovative infrastructure, region, innovative economy, innovative activity.

\section{Source of Financing}

This article was prepared in the framework of the project 19-010-00144 on the topic "Management of innovative development of territories: the concept of "smart specialization" in Russian conditions", with the support of the Russian Foundation for basic research.

\section{References}

1. Vasin, V. A. \& Mindeli, L. E. (2012) [National innovation system in the socio-economic space]. Moscow, IPRAS Publ. (In Russ.)

\section{Conflict of Interest}

The authors declare the absence of obvious and potential conflicts of interest related to the publication of this article.

2. Gamidov, G. S., Ismailov, T. A. \& Tukkel, I. L. (2007) [Innovative economy: strategy, policy, solutions]. Saint Petersburg, Politekhnika Publ. (In Russ.) 
3. Goncharova, E. B. \& Dronenko, D. M. (2013) [Development of the territory's innovative potential (regional and municipal aspects)]. Volgograd, VolgSTU Publ. (In Russ.)

4. Dezhina, I. G. \& Kiseleva, V. V. (2008) [State, Science and Business in Russia's Innovation System]. Moscow, IETP Publ. (In Russ.)

5. Demenok, V. V., Remina, G. V. \& Savanovich, A. V. (2017) [Innovative aspect of small business development in the region]. In [Actual problems of innovative economy and strategic management in the Kaliningrad region: collection of scientific papers BFU named after I. Kant. Kaliningrad], pp. 97101. (In Russ.)

6. Evseev, O. S. \& Konovalova M. E. (2012) [Development of innovative infrastructure in the context of modernization of the national economy]. Fundamental research. 9-1, 220-224. (In Russ.)

7. Zemtsov, S. P. \& Barinova, V. A. (2016) [The paradigm changing of regional innovation policy in Russia: from equalization to smart specialization]. Voprosy Ekonomiki, 10, 65-81. (In Russ.)

8. Zubarevich, N.V. (2015) [Regional Dimension of the New Russian Crisis]. Voprosy Ekonomiki, 4, 37-52. (In Russ.)

9. Kozlov, V. \& Rakul, E. (2018) How to turn innovation into a driver - a version of southern. Retrieved from: https://expert.ru/south/2018/12/kak-prevratit-innovatsii-v-drajver----versiya-yuzhnogo-biznesa/ [Accessed 20 th April 2020]. (In Russ.)

10. Kuznetsov, P. A., Korshenko, O. P. \& Korshenko, I. F. (2013) [Innovative infrastructure for various types of regional innovation development strategies]. Innovations, 10 (180), 51-57. (In Russ.)
11. Kutsenko, E. S., Abashkin, V. L. \& Islankina, E. A. (2019) [Focusing regional industrial policy via sectorial specialization]. Voprosy Ekonomiki, 5, 65-89. (In Russ.)

12. Kutsenko, E. S., Islankina, E. A. \& Kindras, A. (2018) [Smart by Oneself? An Analysis of Russian Regional Innovation Strategies within the RIS3 Framework]. Foresight and STI Governance, 12(1), 25-45. (In Russ.)

13. Medynskiy, V. G. \& Scami, L. G. (2016) Innovative entrepreneurship. Moscow, Infra-M Publ. (In Russ.)

14. Pipia, L.K. (2018) [Modern trends in the formation of scientific and innovation policy]. Innovations, 12, 61-62. (In Russ.)

15. Gokhberg L. (ed.) (2017) Russian Regional Innovation Scoreboard. Moscow, HSE Publ. (In Russ.)

16. Savanovich, A. V. (2016) [On the concept of regional infrastructure development management for small innovative entrepreneurship]. Bulletin of the BFU named after I. Kant, 3, 105-109. (In Russ.)

17. Safiullin, N.F. (2013) [Model of management of innovation development of a territory]. Statistics and Economics, 1, 86-90. (In Russ.)

18. Tatarkin, A.I. \& Sukhovey, A.V. (2017) [Building an innovative economy in the Russian Federation: problems and prospects]. Innovations, 7, 11-15. (In Russ.)

19. Tatenko, G.I. \& Grekova, A.E. (2020) [Innovative infrastructures in Russian and foreign practice]. Economic Science and Humanities, 4(339), 3-14. (In Russ.)

20. Tronina, I.A., Tatenko, G.I. \& Bakhtina, S.S. (2019) [Managing innovative development of territories based on the principles of the European concept of "smart specialization"]. Orel, OSU named after I.S. Turgenev Publ. (In Russ.)
Irina A. Tronina, Dr. Sci. (Econ.), Head of department of Management and public administration, Orel State University named after I. S. Turgenev, Orel, Russian Federation

E-mail: irina-tronina@yandex.ru

ORCID ID: 0000-0002-9593-5129

Galina I. Tatenko, Can. Sci. (Econ.), Assoc. Prof., Department of Management and public administration, Orel State University named after I. S. Turgenev, Orel, Russian Federation E-mail: galinatatenko@yandex.ru ORCID ID: 0000-0002-6491-2370

Alina E. Grekova, Postgraduate Student, Department of Management and public administration, Orel State University named after I. S. Turgenev, Orel, Russian Federation

E-mail: 79208025103@yandex.ru

ORCID ID: 0000-0001-8075-4803

Received 17.06.2020

Accepted 10.09.2020 